\title{
The Turkish Adaptation of Self-Presentation Tactics Scale: Preliminary Results
}

Özlem Serap Özkan*, Gülşah Durna*, Arzu Araz*

${ }^{*}$ Dokuz Eylül University, İzmir/Turkey

\section{Introduction}

Self presentation consists of behaviors which are intended to manage the impressions that observers have of actors (Goffman, 1959). One of the Tedeschi and Melburg (1984)'s classification of self presentational behaviors based on distinction between defensive and assertive behaviors.

The aim of this research to adapt Self-Presentation Tactics Scale (Lee, Brian, Quigley, Nesler, Corbett, and Tedeschi, 1999), which measures self presentation tactics in two distinct components (defensive and assertive) with 12 subscales into Turkish. In the phase of adaptation of the scale, the scale items were initially translated into Turkish by three researchers of the Psychology Department who are proficient in English. For a few items whose translations differed, the evaluations of two more judges from the field of Translation and Interpreting were considered to complete the scale. In the final stage, another researcher in psychology with a degree of English proficiency back-translated the items. It resulted that the translation corresponded to the original scale.

An exploratory factor analysis was conducted in order to determine the construct validity of the measurement tool in the Turkish sample. Testretest reliability and concurrent validity was also tested.

\section{Methods}

Participants

The sample consists of 346 people who are 18 and older. $65.9 \%$ of sample was female and $33.5 \%$ was male. Mean age was 30.33 .

Instruments

Participants' self-presentation tactics with 64 items, self monitoring behaviors with 12 items and age, gender, occupation and income information via demographic information questionnaire were obtained.

Procedure

Data were collected online via Google forms and from Dokuz Eylul University students via paper pencil tests.

\section{References}

Goffman, E. (1959). The presentation of self in everyday life. New York: Doubleday Anchor. Lee, S. J., Quigley, B. M., Nesler, M. S., Corbett, A. B., \& Tedeschi, J. T. (1999). Development of a self-presentation tactics scale. Personality and Individual Differences, 26(4), 701-722. Tedeschi, J. T., \& Melburg, V. (1984). Impression management and influence in the organization. Research in the Sociology of Organization, 3, 31-58.

\section{Structure Validity and Reliability}

The exploratory factor analysis was run with the principal components extraction method, direct oblimin rotation. 13 items which were loaded more than one factor or not loaded any of factors excluded from the scale.

9 factors were extracted with Eigen values higher than one at the final analyses. $58.13 \%$ of the variance was explained by 9 factors. The Cronbach's alpha for the total scale was .93.

Table 1: Min-Max. Factor Loadings and Cronbach's Alpha values for each factor

\begin{tabular}{ccc}
\hline Factors & $\begin{array}{c}\text { Min-Max Factor } \\
\text { Loadings }\end{array}$ & Cronbach's Alpha \\
\hline Ingratiation-Supplication (Assertive) & $.42-.77$ & .90 \\
Apology (Defensive) & $.63-.76$ & .77 \\
Exemplification (Assertive) & $.75-.86$ & .89 \\
Disclaimer-Justification (Defensive) & $.50-.72$ & .82 \\
Intimidation (Assertive) & $.39-.82$ & .76 \\
Justification-Excuse (Defensive) & $.40-.71$ & .80 \\
Enhancement-Entitlement (Assertive) & $.46-.67$ & .81 \\
Self-handicapping (Defensive) & $.56-.67$ & .67 \\
Entitlement-Blasting (Assertive) & $.45-.72$ & .76 \\
\hline
\end{tabular}

Results of the study showed that apology, exemplification, intimidation and self-handicapping items are grouped in separate factors as in the original scale. However, other subscales merged with another subscale in one factor. These combinations may result from the different perceptions about tactics in Turkish sample.

Confirmatory factor analysis will be carried out in order to test the two models (original scale with 12 factors vs. Turkish sample with 9 factors)
Test-retest Reliability and Concurrent Validity

32 (22 female, 10 male) participants from first study completed self-presentation tactics scale 2 weeks later. The test-retest correlation of the total score on the selfAlso, there is a significant correlation between self-presentation tactics and self monitoring $(r=.25, p<.001)$ 